DOI: 10.20472/IAC.2018.040.040

\author{
YUN-HSIEN DIANA LIN \\ National Tsing Hua University, Taiwan \\ SHANG-YUN LI \\ National Tsing Hua University, Taiwan
}

\title{
CHANGING FAMILY FORMATION IN AN ASIAN CONTEXT: SAME-SEX MARRIAGE AND THE LATEST DEVELOPMENTS
}

\begin{abstract}
:
On May 24, 2017 Taiwan's Constitutional Court ruled in favor of allowing same-sex marriage, paving the way for Taiwan to become the first jurisdiction in Asia to legalize same-sex marriage and cementing its status as a beacon for LGBT rights. The Constitutional Court found that Taiwan Civil Code failed to provide two persons of the same gender the right to create a permanent union of intimate and exclusive nature, and such failure violated constitutional guarantees on freedom of marriage. Taiwan's parliament has two years to amend or enact laws addressing same-sex unions, otherwise gay couples will automatically be allowed to register under the current framework.

As above court ruling made activists for LGBT rights proud and excited, how legal experts and lay people in Taiwan see the issue of same-sex marriage is worth exploring. Just a few months before this milestone judicial decision, the author was commissioned by Taiwan Department of Justice to draft Same-sex Civil Partnership Act (the Draft) under the consideration of potential social impact. In this capacity, sessions of focus group discussion were conducted, which consisted experts including family court judges, lawyers and advocates for LGBT rights and children's rights. And in-depth interviews with family law professors were completed to make the content of the Draft comprehensive and the wording more precise. Finally, based upon the theory of deliberative democracy, civil consensus conferences were held in four different cities in Taiwan to dialogue with the public in general on the topic of same-sex unions.
\end{abstract}

The results of this research project reconfirms the diversity of opinions in the Taiwanese society. However, it is revealed that Taiwan's dynamic civil society is the basis for LGBT social movements and the later legal reform. It is also discovered that, to equalize the rights of same-sex partnerships to heterosexual marriages as much as possible is probably the position agreed by most participants of this project.

\section{Keywords:}

same-sex marriage, LGBT rights, social change, children's rights, deliberative democracy 